\title{
Como Proust foi moderno: entre debates literários e conflitos culturais ${ }^{*}$
}

\author{
How Proust Was Modern: between Literary Debates and Cultural Conflicts
}

\author{
Paulo Rodrigo Andrade Haiduke \\ paulohaiduke@yahoo.com.br \\ Professor substituto \\ Universidade Tecnológica Federal do Paraná \\ Avenida Iguaça, 811/505a \\ 80230-020 - Curitiba - PR \\ Brasil
}

\section{Resumo}

Neste artigo são discutidas questões relacionadas ao hoje famoso ciclo romanesco de Marcel Proust (1871-1922) intitulado Em busca do tempo perdido ( $A$ la recherche du temps perdu) e a sua recepção como um dos maiores cânones da literatura moderna no século XX. Tomando como referência comentadores contemporâneos ao lançamento do romance (os volumes foram publicados orginalmente entre 1913 e 1927), pretendo introduzir os leitores nos debates que buscaram arrogar a Proust o papel de arauto do modernismo literário. Dessa forma, apresentarei alguns debates tematizados pelos contemporâneos e que engajaram Proust e sua obra não apenas em querelas literárias, artísticas e estéticas, mas em discussões de maior amplitude social e cultural concernentes à Terceira República Francesa. Utilizarei historiografia específica, bem como bibliografia mais ampla, para mostrar que as querelas nas quais Proust e seu romance foram envolvidos concerniam não apenas ao debate literário e estético, mas também às temporalidades e historicidades de maior amplitude que permearam a sociedade e a cultura francesas.

\section{Palavras-chave}

Terceira República Francesa; Recepção; Modernismos.

\begin{abstract}
This article discusses issues related to the now famous novelistic cycle by Marcel Proust (18711922) titled In Search of Lost Time (A la recherche du temps perdu), and its reception as a major canon of modern literature in the $20^{\text {th }}$ century. Based on critics who were coeval with the launching of the novel (its volumes were published between 1913 and 1927), I intend to introduce the readers in the debates that sought to ascribe to Proust the role of a herald of literary modernism. Thus, I will present a number of theme debates by Proust contemporaries that engaged him and his work not only in literary, artistic and aesthetic disputes, but also in broader social and cultural discussions regarding the French Third Republic. By looking into specific historiographical sources, along with a broader set of bibliographical references, I attempt to show that the disputes in which Proust and his novel were involved concerned not only the literary and aesthetic debate, but also the broader context and historical idiosyncrasies that permeated the French society and culture.
\end{abstract}

\section{Keywords}

French Third Republic; Reception; Modernisms.

Recebido em: 24/12/2013

Aprovado em: 11/8/2014

* Este artigo resulta de uma Tese de Doutorado. A pesquisa foi financiada pela Coordenação de Aperfeiçoamento de Pessoal de Nível Superior (CAPES) mediante concessão de bolsa integral. Durante o doutorado, a CAPES financiou também um período de estágio na França (PDSE). 


\section{Possibilidades de aproximação: modernismo, sensibilidade, visão de mundo}

Aproximar a obra de Marcel Proust do modernismo literário atualmente é como reproduzir um juízo estabelecido e quase um lugar-comum. Porém, nem sempre foi assim, e se há muitos anos Em busca do tempo perdido ( $A$ la recherche du temps perdu) vem sendo tratado pela crítica e pela história literária como um dos grandes cânones modernistas do século XX, isso se deve em grande parte ao processo histórico pelo qual, desde 1913, a obra foi se acomodando na cultura e na sociedade, criando ali suas raízes e sentidos. Um desses sentidos é o de sua novidade literária.

Foram muitos os aspectos salientados pelos comentadores contemporâneos da publicação original que indicavam a obra proustiana como eminentemente modernista. Logo se destacou um juízo que afirmava que Proust era moderno devido às novas formas de sentir e compreender o mundo propostas por Em busca do tempo perdido.

Em 1926, Ramon Fernandez, amigo do romancista e comentador assíduo da obra, enfatizou exatamente esta leitura da sintonia entre o autor e sua época, quando tentava explicar para o público francês mais amplo o fascínio que o livro No caminho de Swann (Du Côté de chez Swann) havia suscitado nele e seu pequeno círculo de colegas. Durante a preparação e publicação do primeiro volume do romance no final de 1913, às vésperas da Grande Guerra Mundial, esses confrades e amigos do autor, que se consideravam então privilegiados, encantaram-se principalmente com a nova concepção e utilização da inteligência por Marcel Proust.

Ramon Fernandez contextualizava sua contemporaneidade como um momento de crise cultural caracterizado pelo divórcio aparentemente definitivo entre inteligência e sensibilidade, sentimento esse que teria sido marcante para sua geração. De fato, Fernandez acaba por afirmar indiretamente a eficaz leitura e interpretação proustiana da realidade ao colocar o autor na posição privilegiada de vanguarda: para ele, Proust teria superado os antigos e ultrapassados mestres da geração anterior - como, por exemplo, Paul Bourget -, incapazes de fornecer doravante alguma alternativa para as novas e inquietas gerações nascidas no final do século XIX e início do XX. Proust, ao contrário, surgia como o novo mestre a ser seguido, visto que sua grandeza estaria no fato de ter reestabelecido uma ligação estreita entre a inteligência e a sensibilidade de seus contemporâneos (FERNANDEZ 1926, p. 203). A leitura da obra de Proust como operadora dessa síntese entre subjetividade e objetividade foi constantemente reiterada durante a publicação dos volumes que formariam Em busca do tempo perdido, sobretudo no período entreguerras. De fato, veremos ao longo deste artigo que foi justamente essa apreciação do romance em questão que acabou muitas vezes sendo usada para identificar Proust como moderno.

Da mesma forma que Ramon Fernandez, Gaston Rageot buscou estabelecer também a conjuntura histórica e literária na qual a obra de Proust emergia. Em conferência apresentada em 1927, Rageot definiu esse momento literário como um período marcado por uma nova sensibilidade do sistema nervoso, oriunda principalmente dos experimentos literários de Charles Baudelaire e Paul Verlaine. 
E no mesmo sentido que Fernandez, Rageot julgou a obra de Proust como uma das raras exceções que conseguia se desvincular da estética estabelecida, conseguindo assim unir as correntes da sensibilidade e da psicologia (RAGEOT 1927, p. 336-349).

No fundo, o que esses comentadores e defensores da obra de Proust destacavam era um problema que já estaria posto no contexto anterior à obra, uma espécie de impasse histórico enfrentado pelas novas gerações e que consistiria na falha da psicologia e da sensibilidade tradicionais, ou melhor, numa incompatibilidade entre ambas (a mesma que apontava Ramon Fernandez). Logo, Proust teria sido aquele que, para Fernandez e outros contemporâneos, conseguiu criar uma nova inteligência e compreensão do mundo, mas partindo exatamente da sua sensibilidade nervosa e moderna.

Essa capacidade de captar e, principalmente, de dar a ver ao público uma nova realidade pela arte é comumente tratada pela crítica literária como uma das principais marcas do modernismo. Segundo Jean-Michel Rabaté, a tentativa do modernismo de transformar a linguagem partiu de uma busca voluntária e consciente de estranhamento a fim de desestabilizar os hábitos comuns e tradicionalmente estabelecidos de ver, pensar e compreender. Logo, a complexidade e consequente inacessibilidade do modernismo sentidas por grande parte do público não eram resultado do acaso ou da incapacidade de criação. Ao contrário, elas eram um efeito buscado justamente para obrigar o leitor a relacionar-se com o mundo de maneira diferente e, assim, desabituá-lo (RABATÉ 2009, p. 887-918).

A obsessão da época pelo problema da disparidade entre sensibilidade e inteligência, que dá origem a diversas outras polarizações como arte e ciência, expressa a demanda na época de novas visões de mundo. E foi exatamente a essa demanda que Em busca do tempo perdido respondeu aos olhos de diversos contemporâneos.

Do exposto até aqui podemos discernir que a literatura, nesse contexto, estava inserida em um debate mais amplo da cultura que dizia respeito à percepção, apreensão e conhecimento do mundo. Esse foi um dos importantes debates, portanto, no qual a obra de Proust se inseriu no momento de sua publicação, o que fica evidente quando se toma por base sua recepção, bem como a própria obra. Seu destaque nesse debate advém justamente da tomada, no seio do próprio Em busca do tempo perdido, dessa questão como objeto de especulação literária. Conforme Compagnon, Proust dramatizou mais do que qualquer outro romancista a própria cultura (COMPAGNON 1992, p. 955).

Se de fato Em busca do tempo perdido não teve a recepção de um público mais amplo - e por conseguinte não pode ser considerado o principal romance francês da época no que tange à difusão -, isso não impediu absolutamente o grande impacto que a obra de Proust teve dentro da literatura francesa desde sua publicação. Com efeito, Marcel Proust foi e tem sido considerado, desde 1913 (claro, com alguns momentos de estagnação e arrefecimento), como o autor de uma obra literária crucial para a compreensão do debate cultural e intelectual francês durante a Terceira República. Isso foi visto tanto de maneira 
positiva quanto negativa pelos leitores e comentadores do romance proustiano, pois, se alguns o leram como uma resposta à crise cultural sentida, outros, pelo contrário, não deixaram de apontá-lo como sendo, se não a causa principal da degeneração moderna no período pós-guerra, no mínimo como uma enorme influência malsã para as novas gerações.

Tais juízos sobre a obra de Proust apontam para a interpretação da singularidade histórica que os leitores viam em sua própria época: uma modernidade cujos presente e imediato passado eram vistos como marcando uma conjuntura específica na história que, consequentemente, demandava uma nova maneira de ver e de ser representada. Henri Lefebvre sintetizou muito bem esse sentimento, na revista Philosophies de 15 de maio de 1924, ao expressar como sua contemporaneidade legava às últimas décadas uma especificidade histórica que teria sido bem captada por Em busca do tempo perdido: para ele, a análise de Proust mostrou que o espírito moderno demandava então uma nova filosofia da consciência e uma amplificação da noção de universalidade (LEFEBVRE 1924, p. 225-227). Logo, nesta perspectiva de Lefebvre, a obra de Proust aparecia como resposta à demanda do espírito moderno. Essa nova consciência representada em sua obra poderia assim apreender, representar e dar a ver novas e insuspeitas realidades, justamente por atender às necessidades de uma conjuntura que reclamava do divórcio entre a sensibilidade e a razão. Neste momento cabe introduzir uma importante digressão para analisar melhor algumas questões importantes relativas à história dessa crise e polarização entre a sensibilidade subjetiva e a consciência objetiva apontada pelos comentadores de Em busca do tempo perdido como um problema profundamente importante daquela conjuntura.

\section{Entre arte e sociedade moderna: crises culturais, perda e busca de identificação}

Como dissemos anteriormente, a obra de Proust foi discutida em debates culturais mais amplos da sociedade francesa, sendo considerada tanto como uma resposta quanto como uma das responsáveis dos problemas em questão. Essa forma de recepção não foi um privilégio da obra proustiana, sendo muito pelo contrário praticamente uma constante na história da maioria das produções artísticas modernistas. De fato, se a arte se incumbia muitas vezes de dar respostas a algumas questões levantadas na época, por outro lado as ditas obras modernas eram acusadas de causar o dilaceramento da personalidade.

Tal posição paradoxal do lugar social da arte no período advém em parte das suas novas funções dentro das sociedades europeias oitocentistas. Segundo Peter Gay, o modernismo: "gerou uma nova maneira de ver a sociedade e o papel do artista dentro dela, criou uma nova forma de avaliar as obras culturais e seus autores" (GAY 2009, p. 19).

Porém, o modernismo artístico, direta ou indiretamente, acabara também se engajando em outra crise latente e de maior duração histórica. Embora Jean-Michel Rabaté afirme que foi uma nova subjetividade que demandou o modernismo literário - e nesse ponto ele estaria de pleno acordo com os comentadores da obra proustiana - , ele não está tão seguro em apontar o momento em que isso ocorrido, 
destacando assim a enorme dificuldade de periodizar tal mudança (RABATÉ 2009, p. 887-918). De qualquer forma, podemos concluir que essas interações entre artes, sociedade moderna e sensações de crise não são aspectos exclusivos desse contexto do final do século XIX e início do século XX francês. Embora seja difícil determinar sua origem, há uma história que pode ser remontada, para os objetivos do presente trabalho, pelo menos ao século XVIII.

Podemos tomar como pista um texto de 1902, no qual Georg Simmel buscou definir os grandes dilemas da sociedade moderna, pois nele expressa sua opinião como contemporâneo do período estudado:

Os problemas mais graves da vida moderna derivam da reivindicação que faz o indivíduo de preservar a autonomia e individualidade de sua existência em face das esmagadoras forças sociais, da herança histórica, da cultura externa e da técnica de vida. [...] O século XVIII conclamou o homem a que se libertasse de todas as dependências históricas quanto ao Estado e à religião, à moral e à economia (SIMMEL 1967, p. 13).

O século XVIII é destacado, portanto, como fomentador do ideal de homem moderno e como uma terra natal da modernidade do início do século XX por Simmel. E o desenvolvimento do realismo literário moderno estaria intrinsecamente ligado a essa questão na medida em que a busca pela desvinculação das coerções externas que entravavam a realização do ideal emancipatório e esclarecido do homem moderno impulsionou o realismo literário na busca dessas forças externas que cerceavam a vida e a experiência humanas.

Se primeiramente essas limitações foram vistas como externas ao homem, com o advento e desenrolar do século XIX surgiram novos problemas, e as coerções e limitações ao desenvolvimento do ideal do homem moderno esclarecido passaram a serem vistas como formadoras incontornáveis da sua experiência e identidade. Em outras palavras, a confiança do homem moderno era então questionada pela sua exposição inexorável e incontornável à realidade na qual estava inserido, transpassado como era por aquilo que Foucault chamou de uma das grandes viradas da episteme ocidental no início do século XIX (FOUCAULT 1992, p. 384-385). Dessa forma, alguns fatores que outrora permaneciam inconscientes passaram a exigir do sujeito desde então uma nova atitude, pois ameaçavam sua almejada liberdade subjetiva plena e, consequentemente, a realização do espírito livre moderno profetizado por Nietzsche (2000). Isso explica em parte por que Proust deu tanta atenção em sua obra ao que denominou memória involuntária como dimensão mais profunda e real da subjetividade que devia ser escavada.

Essas questões expressavam na verdade problemas e crises culturais que concerniam principalmente à tentativa de construção moderna da identidade. De fato, no Em busca do tempo perdido, o narrador busca compreender sua trajetória e identidade durante essa conjuntura na qual seus contemporâneos crescentemente se voltavam em direção às dimensões inconscientes do homem. Jacques Le Rider realizou interessantes análises acerca da modernidade vienense do final do século XIX, enfatizando o papel da desestabilização das identidades na cultura da época e suas relações com o advento da psicanálise: 


\begin{abstract}
À luz da psicanálise, o sentimento de identidade de cada sujeito aparece como um jogo constante e imprevisível onde se combinam e se opõem a identidade consciente e algo inconsciente, a identidade de projeção no futuro e a que se alimenta de recordação; a identidade de pertencer a uma família, a um grupo ou a um povo, e a que passa pela rejeição das dependências, da "normalidade"; a identidade atribuída pela vida (o sexo, a raça, a época, etc.), e a aspiração à negação e à ultrapassagem desses limites. O enfoque psicanalítico confirma também que, para o destino do sujeito, os fantasmas da identificação podem suplantar a identidade "real", ao ponto da oposição entre a realidade e o fantasma não possuir mais nenhuma significação quando se busca compreender uma personalidade (LE RIDER 1993, p. 77).
\end{abstract}

Este é o momento da terceira ferida narcísica da cultura ocidental destacada por Foucault: como acontecera com ocasião das duas primeiras feridas, ela traz em seu bojo novos dilemas e crises culturais (FOUCAULT 2005, p. 5152): o indivíduo moderno deixou então de acreditar em seu total controle e consciência sobre as forças que o dominavam. Isso significava um obstáculo para o desenvolvimento do seu ideal moderno de emancipação e esclarecimento. E a arte moderna, em seu reiterado engajamento contra o clássico, o tradicional e o estabelecido, encenou repetidas vezes nessa história o papel de resistência em favor da emancipação e da autonomia.

O problema surge aqui como espécie de efeito colateral de uma das principais marcas desse modernismo: o senso crítico altamente desenvolvido; pois, se ele age em favor da emancipação moderna, enfrentando e denunciando as forças tradicionais que coagem o homem e determinam sua existência, acaba sendo também, e justamente por conta disso, uma das causas do desencantamento moderno. Por isso, os críticos Ramon Fernandez e Gaston Rageot enfatizavam a necessidade de mesclar a inteligência com a sensibilidade. Muitos outros críticos que emitiram juízos sobre a Em busca do tempo perdido salientaram a eficaz síntese entre subjetividade e objetividade operada pela representação literária proustiana. De qualquer forma, esses exemplos mostram que este foi um momento no qual as certezas mais sólidas estavam sendo colocadas em questão, o que acabou se configurando também como elemento de dissolução da cultura estabelecida, aceita e partilhada pela sociedade. E nesse processo histórico, o modernismo literário não apenas se engajou nas principais questões culturais, mas foi inclusive visto repetidas vezes como uma das causas que exerceu importante papel na eclosão de tais crises culturais. Isso significa não apenas que escritores como Proust problematizaram voluntariamente temas caros às suas contemporaneidades, mas que suas obras foram mobilizadas pela exegese crítica tanto para condenar quanto para enaltecer os tempos modernos.

\title{
A metrópole e o advento da sociedade de massa: espaços de experiência moderna e engajamento artístico
}

Segundo Richard Sennett, os códigos de expressão pública passaram a valorizar o detalhe de maneira crescente, tornando-se quase uma obsessão, durante o século XIX nas capitais europeias como Paris e Londres, por exemplo. 
Isso aponta para o que foi apresentado acima, esse ansioso interesse que o século XIX nos legou pelo encontro da realidade subjacente à aparência e que alcançou seu signo pleno com o advento da psicanálise. Logo, o advento desta nova urbanidade seria, nessa perspectiva, resultado da pressão criada pelo vertiginoso crescimento demográfico e pelo capitalismo industrial, forças e agentes de mudanças de grande amplitude ao longo do século XIX (SENNETT 1999).

É nessa metrópole, apresentada como local de estranhos e de segredos, que a busca pelos detalhes se torna um método de apreensão de realidades não só materiais, mas também humanas, pois tais minúcias individuais seriam compreendidas desde então como as chaves para entender comportamentos e personalidades. Isso parece condizer com a opinião de Georg Simmel de que a impessoalidade da vida nas grandes metrópoles gerou, como contraponto, uma subjetividade altamente pessoal (SIMMEL 1997, p. 18). Críticos que comentaram a união entre a objetividade e a subjetividade na obra proustiana constantemente exaltaram sua perspectiva subjetiva da realidade das coisas e dos seres. Em suma, salientavam que o resultado disso era uma espécie de realidade objetiva subjetivada, uma representação da realidade oferecida como resultado de um olhar individual que não era onisciente em relação ao que narrava.

Essa busca pelo detalhe, destacada como elemento formador da subjetividade moderna e auxiliar do homem para se localizar e se inserir no espaço urbano, tem mais valor ainda para uma forma de discurso como o romance, que, na tentativa de descrição e análise da vida moderna, não deixa de atentar para os detalhes cotidianos. Conforme Sennett:

Tudo da sociedade está miniaturizado em cada pequena manifestação concreta da vida, mas o romancista e o leitor de romances devem se esforçar para aplicar cada uma de suas faculdades, para investir mais sentimentos nos detalhes do que poderiam confirmar logicamente, a fim de arrancar esse segredo. Pequenas ações, pequenas coisas da vida, não têm qualquer significação clara sem esse esforço (SENNETT 1999, p. 198).

Mas se o modernismo é um dos agentes dessa valorização dos detalhes, isso decorre justamente da sua necessidade de inserção nas questões culturais das quais é contemporâneo. Conforme Malcom Bradbury, a arte moderna tem como dever vanguardista essa obrigação de engajamento nas querelas culturais e nesses contextos de aparente crítica e crise. Bradbury vê o modernismo como uma revolução artística profunda gerada, sobretudo, pela crise na história do humanismo ocidental e pela busca de compreensão da existência moderna. Logo, essa profunda sensação de colapso da cultura europeia tradicional dava vazão às reivindicações das artes modernas por renovações culturais e morais. Tratava-se da afirmação de uma arte de crise que se propunha também como possibilidade de superação desses aspectos desagregadores da vida moderna (BRADBURY 1989).

Em uma homenagem a Marcel Proust publicada pela efêmera revista literária Le rouge et le noir em 1928, Pierre Quesnoy, preocupado com a moralidade moderna e sua relação com a obra de Proust, afirmava que vivia numa época 
fortemente preocupada com a moral. Muito mais que em tempos anteriores, o homem moderno estaria preocupado com a moral para compreender, na verdade, uma realidade anterior e inicial (QUESNOY 1928, p. 94). Podemos concluir dessas questões de Quesnoy que a busca da espontaneidade, pureza e sinceridade surgia então como uma tentativa de suspensão dessa moral fundada na artificialidade da civilização e das repressões impostas pela sociedade moderna.

Isso explica em parte como a obra Em busca do tempo perdido pôde ser tomada como referência em debates sobre problemas culturais importantes na época: ao buscar uma realidade humana primeva, conforme afirma Quesnoy, ela se colocava também como espaço de problematização e avaliação da realização ou não do projeto de esclarecimento e emancipação do homem moderno. É o que Bradbury chama de uma nova consciência revolucionária, crítica e sensível, sobretudo, à aceleração histórica e ao seu respectivo impacto no indivíduo; daí o fator inconsciente da literatura moderna, pois o efeito de tal impacto era cada vez mais sentido, ao longo do século XIX, como agindo de maneira obscura, imperceptível e misteriosa (BRADBURY 1989, p. 25-26).

Para Richard Sennett, desde Jean-Jacques Rousseau a experiência moderna já partia em busca do verdadeiro eu como resposta à opressão sentida pelas estruturas materiais, sociais e culturais da cidade grande moderna (SENNETT 1999, p. 153-154). Daí resultou que o cultivo da personalidade foi elevado a ideal, pela sua suposta promessa de realização da liberdade e do esclarecimento. Mas o que nós vemos se destacar nas leituras e comentários sobre Proust é a constatação (muitas vezes somada à acusação) da dissolução da personalidade operada ou anunciada por sua obra. Para Henri Massis, em consonância com muitos críticos da arte modernista na França durante a década de 1920, o problema principal era a dissolução da personalidade operada por tal movimento, que se fazia sentir nas manifestações contemporâneas da então jovem literatura, principalmente entre os discípulos de André Gide e Marcel Proust (MASSIS 1927, p. 72-73). Tal juízo mostra claramente uma avaliação de Proust como moderno, porém de forma negativa e contrária ao apontado pelos comentários de Fernandez e Rageot citados no início deste artigo. À diferença desses últimos, que consideravam Em busca do tempo perdido como uma obra moderna por tomar para si a tarefa de resolver problemas que lhe eram contemporâneos, Massis considerava-a como uma espécie de causa da crise de identidade que identificava entre seus contemporâneos.

Porém, as artes modernas não eram em si as causadoras da dissolução nem as principais fomentadoras; e, se foram sentidas como tal, isso se deveu antes de tudo à função de que se incumbiam, a de expressar em forma estética as sensações e impactos dessa dissolução do sujeito e da própria arte como a inegável realidade moderna. Logo, as artes modernas em geral não geraram as crises modernas, mas lhes deram corpo e voz, expressando e deflagrando aquilo que era sentido como crise. De fato, havia elementos estruturais e formadores da grande modernização ocorrida nas capitais europeias ao longo do século XIX mais cruciais para o surgimento da sensação de desenraizamento 
moderno, como o advento da metrópole aliada à revolução industrial e a consequente crise dos valores e padrões culturais tradicionais que eram vigentes e sustentavam a sociedade.

\section{Paradoxos e contradições da experiência moderna: entre a decadência fin-de-siècle e a Grande Guerra}

A modernização do século XIX, impulsionada pelo emergente capitalismo industrial e apoiada pela crescente urbanização, levou ao otimismo decorrente do desenvolvimento material, tecnológico e científico e da materialização do progresso. Porém, esse processo também foi sentido, e de maneira crescente, com a aproximação do fim do século, como desestabilizador das bases tradicionais da sociedade. Para Richard Sennett, o impacto do capitalismo na vida pública oitocentista foi determinado por uma produção de massa que acabou homogeneizando os padrões de consumo e também os consumidores (SENNETT 1999). Isso representava um problema para aqueles entre os quais os valores tradicionais hierarquizados remanescentes do Antigo Regime eram arraigados.

Para Jacques Le Rider, a modernização operada nas grandes capitais europeias durante o século XIX foi a grande causa das mudanças na experiência moderna no início do século XX e também das reações culturais como a representada pelas artes modernas:

A modernização do século dezenove se caracteriza pela expansão da administração do Estado, o progresso científico e técnico engendrando mudanças sociais e a perda de determinadas tradições culturais, o crescimento demográfico e econômico, a urbanização e o desenvolvimento de meios de comunicação e de informação. Estas mutações conduziram a uma redefinição dos termos do debate que parece agora indispensável ressaltar. A modernização, processo econômico, social e político, questiona a identidade cultural das coletividades e as identidades subjetivas dos indivíduos. O modernismo corresponde ao endurecimento doutrinário das "ideias modernas", em primeira instancia da ideia de progresso, inclusive nos campos artístico e religioso. Por fim, a modernidade designa um modo de vida, de pensamento e de criação, que não se furta ao imperativo de mudança e inovação, ao mesmo passo conservando consciência crítica em relação à modernização, expressada em termos estéticos ou teóricos, e ao tomar distância em relação ao modernismo. Em Baudelaire, a virulenta denúncia do mundo presente se conjuga com a exaltação do moderno. Do mesmo modo, a modernidade vienense se revela em muitos aspectos antimoderna (LE RIDER 1993, p. 47-48).

Essa relação paradoxal entre o homem moderno e a modernização é justamente o núcleo pelo qual surge a ferida narcísica no ideal da modernidade iluminada do século XVIII. Eis que aparece certa angústia pela qual o indivíduo passa a observar sua própria posição paradoxal: ele é exaltado como realização do ideal de homem moderno, mas também visto como responsável pela crise cultural e a dissociação da personalidade em função de seu exagerado individualismo.

Tal posição paradoxal é análoga à ocupada pela literatura modernista, como podemos ver claramente exemplificado na descrição da figura de Proust publicada por Roger de Lafforest e Emile Pirel em La gazette française de 18 
de outubro de 1924. Após acusar Em busca do tempo perdido de ser uma obra comprometida devido à representação da dissolução do indivíduo e de ser uma obra incapaz de representar o movimento da vida, os autores concluem que isso, na verdade, era uma característica da literatura contemporânea. Para os autores, existiam algumas exceções, mas que apenas fugiriam discretamente à regra da geração literária da qual Proust era o mais perfeito representante (e isso não significava absolutamente um elogio) (LAFFOREST; PIREL 1924a).

Tal crítica vem da nova posição da arte no contexto da época e da tomada de consciência, no mínimo relativa e turva, dessa novidade por parte dos representantes do campo artístico e literário, tais como críticos, editores e artistas. Nesse sentido, a obra de Proust é significativa, pois é sentida de maneira crescente ao longo da década de 1920 como um dos maiores acontecimentos literários da época: seu romance e a respectiva crítica foram não apenas uma espécie de termômetro de uma conjuntura histórica em que a sensação de crise cultural foi aguda, mas acabaram funcionando de maneira ímpar e crucial no debate decorrente.

Segundo Peter Gay, era praticamente um chavão durante o século XIX referir-se à época como um "tempo da transição". De fato, as capitais europeias mudavam mais rápido do que nunca: "No intervalo da vida de uma pessoa estas cidades mudaram a ponto de se tornarem irreconhecíveis" (GAY 1988, p. 45). Esse sentimento de transição, com a aproximação do fim do século, passou a responder cada vez mais a uma visão de que se entrava na era da decadência da humanidade.

O interessante a destacar aqui é, portanto, que a busca da verdade pessoal foi tomada como um dos princípios da arte moderna, fundamento pelo qual ela se opôs diversas vezes às estruturas sentidas como limitadoras ou determinantes da vida humana (FOUCAULT 2001). Isso fica claro no trabalho de Eric Auerbach, que destaca como um dos principais elementos do realismo moderno a problematização moderna mais aguda e atenta à dimensão temporal da realidade (AUERBACH 1976, p. 463). Isso porque, em parte, essa parcela histórica da realidade era cada vez mais vista como formadora da cultura, da sociedade e do próprio indivíduo.

Portanto, tal aproximação entre arte, conhecimento e busca da verdade foi se tornando uma das principais marcas da modernidade no final do século XIX. Conforme Anne Henry, nesse momento da história, a arte buscava interrogar e interpretar o mundo ao seu modo e abandonar os métodos de representação até então admitidos, o que fazia do estilo um método de aproximação da verdade buscada (HENRY 1986, p. 15). Em busca do tempo perdido inserese nessa conjuntura que idealiza a construção de uma era nova pautada na revisão modernista e por isso expressa o conflito entre o progresso irreversível do discurso científico e a descrença no poder último do racional. Disso, a autora conclui que, tematizando e utilizando as ciências humanas num romance que dá tanto espaço à especulação, Proust imaginava que poderia conseguir a reunião entre arte e ciência (HENRY 1986, p. 77). Ao menos, como ficou claro até agora, o romance proustiano foi seguramente lido como uma tentativa (e às 
vezes com sucesso) dessa síntese. E como já destacamos no começo, esta é a mesma simbiose entre sensibilidade e inteligência pela qual ele foi muitas vezes recepcionado pelos contemporâneos como romancista moderno.

Neste ponto, é interessante voltar à questão da dissolução da personalidade, para entender como o modernismo literário a tomou como seu objeto e a trabalhou. Para Luiz Costa Lima, a poesia de Arthur Rimbaud representaria, na segunda metade do século XIX, justamente a crise de identidade na sociedade francesa (LIMA 1980, p. 150). Tal crise de identidade é uma constante no contexto do final do século XIX e início do século XX na França, e a obra de Marcel Proust foi lida também como uma dramatização possível dessa questão.

Porém, se, como vimos, o sentimento genérico de crise é algo que talvez não caracterize exclusivamente o contexto do final do longo século XIX, ele possuía nessa época uma particularidade que está indicada pela própria noção de decadência fin-de-siècle. As correlativas noção e sensação foram definitivamente corroboradas por um acontecimento sem precedentes para a Europa, sentido como a grande e definitiva ruptura com a Velha Europa: a Grande Guerra de 1914-1918, que veio confirmar todas as visões de crise, bem como sua culminação na maior de todas as catástrofes possíveis e prenunciadas. André Chaumeix, na Revue de deux mondes de primeiro de abril de 1928, ou seja, distanciado já da guerra por dez anos, critica a obra de Proust por expressar a desagregação da personalidade, embora culpe não o autor e sim a guerra como causa dessa postura. Segundo ele, Em busca do tempo perdido negligencia o

100 que há no homem de superior à natureza, o que mostraria, na sua opinião, que a literatura do pós-guerra era desprovida do senso humano espiritual e interior; ou seja, Chaumeix interpretava toda a literatura contemporânea como reflexo da desordem que a guerra havia lançado sobre as "sociedades civilizadas" (CHAUMEIX 1928, p. 701). Disso o autor conclui que os homens estavam desde então fora da ordem comum, que todas as noções estavam abaladas e que a desordem da personalidade era o mais notável elemento da literatura romanesca.

\section{Em busca do tempo perdido entre dois séculos}

Escrita nos anos que precederam a Guerra, o primeiro volume de Em busca do tempo perdido foi publicado no final de 1913, às vésperas do grande conflito. Anunciada então como uma trilogia que seria finalizada no ano seguinte, a edição acabou por ser interrompida e adiada até o período posterior à guerra. Assim, em 1919, o segundo volume era lançado, mas já divergindo do plano anterior, pois, nesse intervalo, Marcel Proust não cessara de incorporar novos elementos ao projeto da trilogia original, o que fez inclusive até sua morte em novembro de 1922.

Seu romance, contando os livros que publicou em vida e os volumes póstumos organizados pelo amigo Jacques Rivière e por seu irmão Robert Proust, acabou somando oito tomos (ultrapassando a duplicação do projeto inicial). Entre 1913 e 1922, podemos notar claramente que Proust incorporou eventos e fatos marcantes da história contemporânea, sobretudo a Grande 
Guerra, tomada inclusive como uma explicação central para as hipóteses de mudanças sociais apresentadas pelo Em busca do tempo perdido.

Vemos assim que salvo No caminho de Swann, todos os outros volumes foram escritos e publicados ou numa atmosfera de generalizado conflito armado entre a França e a Alemanha, ou nos anos que viveram o trauma subsequente. Logo, a obra proustiana e a guerra estão, por conta de diversos aspectos, incrustadas uma na outra de maneira praticamente inseparável, o que foi ressaltado e reforçado pela recepção de Em busca do tempo perdido na época.

Segundo o crítico Bernard Faÿ em livro de 1925, a guerra influiu diretamente nos rumos da história literária francesa, fundando-se como momento de grande agitação universal das condições de vida. Entre suas principais consequências, Faÿ destaca o imenso e derradeiro fracasso dos cânones literários vigentes até 1914, os antigos baluartes da representação coletiva francesa, como Maurice Barrès, Anatole France e Romain Rolland. Eles não podiam mais responder aos anseios das gerações crescidas, educadas e traumatizadas nesse contexto, surgindo, então, o momento propício para uma nova geração de escritores (como Marcel Proust, André Gide e Paul Valéry) ganharem prestígio e espaço (FAŸ 1925). Tal juízo de Bernard Faÿ é extremamente significativo, pois expressa a opinião segundo a qual Proust fazia sucesso por saber se comunicar melhor e apresentar uma visão de mundo mais legítima nessa conjuntura posterior à guerra.

Proust, que começou a escrever Em busca do tempo perdido anos antes de 1914, mas que no volume publicado no fim de 1913 já descrevia uma profunda sensação de crise na época moderna, teve na guerra, como muitos artistas de então, o tema e a justificativa perfeitos para dar o cunho de uma grande ruptura na história contemporânea. A guerra, de fato, ajudou muito o escritor a transmitir uma sensação maior de distanciamento entre o passado idealizado da juventude do seu narrador (la fin-de-siècle e a Belle Époque) e o presente pós-guerra como tempo da narrativa.

Esse distanciamento entre passado e presente destacado exerce na verdade uma função dramática central dentro do romance, pois, se há o distanciamento, ele advém de uma operação diametralmente oposta, que consiste justamente em mostrar a sobrevivência do passado no presente através de suas ruínas. É essa identificação com o passado, através dos monumentos remanescentes da história, que passa a ser impedida com a eclosão da Grande Guerra.

A capacidade de Proust para inserir no Em busca do tempo perdido acontecimentos contemporâneos servindo-se de um processo de escrita quase infinito, sem dúvida, foi uma das causas pelas quais sua obra foi repetidamente vista como um relicário da história e da memória do período. Mas Marcel Proust teria sido de fato o principal satirista e último historiador dessa cultura supostamente em decadência? Muitos leitores contemporâneos viram-no assim e leram sua obra como uma representação válida da realidade do final do século XIX e das primeiras décadas do século XX. De qualquer maneira, os textos que compõem sua recepção demonstram que os lançamentos dos sucessivos volumes de Em busca do tempo perdido foram acompanhados de 
uma cristalização crescente da obra como um dos grandes acontecimentos literários da França, se não o maior da época.

Jean de Pierrefeu, no jornal Le quotidien de 12 de julho de 1926, expressa claramente a opinião de que a obra de Proust era singularmente excepcional: ela marcaria, na sua opinião, o início de uma verdadeira revolução literária; dessa forma, Proust era apresentado como o evento literário mais importante dos tempos modernos. O crítico do Quotidien interpreta esta nova era da literatura como um resultado da renúncia proustiana à pura objetivação intelectual, que Pierrefeu considera um atributo usual da representação literária até esse momento. Nesse sentido, Proust era entendido como uma espécie de escritor impressionista, que se voltava não para o objetivo em si, mas sim para a imagem que o suposto objeto teria deixado durante o processo de introjeção pela consciência (PIERREFEU 1926).

No entanto, cabe observar que, se o romance de Proust era sentido como um acontecimento significativo que marcaria duradouramente a literatura francesa em seu conjunto e, consequentemente, a cultura francesa como um todo, isso não ocorreu em 1913, com o início da publicação da obra, mas só no período pós-guerra, a partir de 1919. Isso evidencia que a guerra, direta ou indiretamente, influenciou no sucesso de Em busca do tempo perdido. E isso aconteceu tanto pelo novo clima da sociedade instaurado após o conflito, como pela própria mudança que causou no projeto criador de Proust e no texto final da obra.

De fato, como afirmou Bernard Faÿ, a literatura sofreu grandes mudanças 102 em consequência da guerra, pois a tematização da guerra e do nacionalismo passou a ser quase obrigatória nas obras literárias produzidas entre 1914 e 1918. Durante a guerra, a literatura havia-se engajado com sucesso em representar o conflito beligerante, adotando uma espécie de obrigação e decoro social que impedia a tematização de assuntos considerados frívolos quando comparados com a guerra. Porém, a partir de 1919, houve certo esgotamento não apenas do assunto, mas da própria vontade dos franceses em continuar exclusivamente atrelados ao traumatizante evento. Isso fez com que a questão do engajamento ou não da literatura retornasse com toda força nesses anos subsequentes à guerra.

Em 1919, em sua coluna sobre literatura no jornal Comoedia, Binet-Valmer expressou essa sensação de esgotamento da literatura patriótica como introdução ao seu comentário sobre o segundo livro de Em busca do tempo perdido, $\dot{A}$ sombra das raparigas em flor (A l'ombre des jeunes filles en fleurs). Em sua posição sempre ambígua e irônica facilitada pela apresentação em diálogo de sua coluna, o crítico do Comoedia afirmava que negligenciaria voluntariamente todas as obras da guerra, destacando assim a necessidade de mudança (BINET-VALMER 1919).

Contudo, para alguns críticos como os já citados Roger de Lafforest e Emile Pirel, a guerra havia ensinado o verdadeiro valor da vida, diametralmente oposto para eles dos valores encontrados na então prestigiada obra proustiana. Esses autores chegam a enfrentar abertamente o que chamam de perigo intelectual representado pela obra de Proust no sentido de que impediria o aperfeiçoamento das almas (LAFORREST; PIREL 1924b). 


\section{Em busca do tempo perdido como acontecimento literário: questões} sobre o modernismo e a experiência moderna no início do século $\mathbf{X X}$

Esse modernismo com o qual Proust foi muitas vezes identificado na época foi, portanto, constantemente atacado, devido ao seu suposto potencial de perigo para a cultura clássica e tradicional. Em, o crítico do Correspondant Armand Praviel julgou em seu artigo que, se as gerações vindouras fizessem de Proust o autor preferido, isso significaria o fim da cultura grega e romana e do próprio classicismo francês (PRAVIEL 1923, p. 86).

Dessa forma, ao tomar como privilegiado objeto e problema as crises de identidade do homem moderno, o modernismo se engajou em questões culturais cruciais, mas, consequentemente, foi também apontado como causa do problema. Por isso, um dos temas principais de Em busca do tempo perdido, que é a sensação de não identificação com a realidade contemporânea e que se expressa na história dramatizada pela trajetória do narrador proustiano, foi interpretado por parte da crítica como sendo na verdade uma das causas da própria falta de identificação.

Essa incapacidade do indivíduo para dar sentido ao mundo que o circunda, essa perda de realidade, é exatamente o que o narrador destaca ao final de No caminho de Swann, quando afirma retrospectivamente que o mundo em que levara sua vida não mais existia. Retornando a Simmel, Jacques Le Rider destaca essa crise de identidade de final do século XIX:

Por nossa parte, insistindo sobre a crise do individualismo pós-moderno e seu corolário, a crise de identidade, retomamos de certa forma as análises de Georg Simmel que mostravam como o homem moderno, único responsável por ele mesmo em relação aos valores, permanece constantemente inquieto: "Porque a essência do moderno", escrevia Simmel, "é o psicologismo, o fato de sentir e interpretar o mundo de acordo com as reações de nossa interioridade, como um mundo interior, trata-se da dissolução dos conteúdos estáveis da subjetividade" (LE RIDER 1993, p. 50-51).

Assim, aqui, Simmel é destacado pela sua visão do homem moderno como intrinsecamente marcado pela dissolução.

Com efeito, vemos que há uma ligação íntima, segundo os diagnósticos da modernidade até aqui apresentados, entre a experiência do homem moderno ao longo do século XIX nas metrópoles, a crescente sensação de separação da realidade e a dissolução de sua personalidade.

Esses são apenas alguns aspectos, mas muito relevantes para o presente artigo, da experiência humana nessa modernidade que teve como palco preferencial a vida na metrópole. Segundo Peter Gay, a experiência é fruto do encontro entre a mente humana e o mundo circundante (entendido como realidades objetivas que jamais serão refutadas). Nesse sentido, ela aparece como tráfego ininterrupto entre o que o mundo fornece e impõe; e o que a mente exige, recebe e reformula, legando à cultura o papel de fornecer material ao sujeito para construir e dar sentido ao mundo (GAY 1988, p. 19). 
Isso nos permite observar esta parte da cultura do final do século XIX, que se cristalizou sob os signos da decadência e da crise moderna, como artefatos de leitura e apreensão da realidade que eram utilizados e difundidos na sociedade da época. Em parte, essa conjuntura é consequência da vida na metrópole moderna, que não só possibilitou, mas exigiu uma nova atitude do homem diante dela, gerando novas experiências pelas quais os indivíduos tentavam criar novas estratégias e ações de identificação com a realidade.

Eric Auerbach, analisando o realismo moderno do período entreguerras, destacou a sensação de fim do mundo como constante em todas as obras do período, o que inclui Em busca do tempo perdido (AUERBACH 1976, p. 496). Tendo em vista que essas obras e esse discurso de fim do mundo alcançaram tanto sucesso, tornando-se inclusive os maiores cânones da literatura ocidental do século $X X$, é inegável que tal visão do mundo era respaldada e aceita como legítima por grande parte da sociedade. Isso explicaria parcialmente por que o modernismo se tornou mais relevante nas artes no pós-guerra, bem como a (em geral) favorável recepção da obra de Proust, que, com isso, confirmava a visão antes referida.

Por outro lado, a década de 1920 foi sentida como de grande florescência artística. Para Albert Thibaudet, um dos críticos franceses mais respeitados e prestigiados do período entreguerras, o prêmio literário Goncourt concedido a Proust em 1919 seria inclusive marco para uma nova época literária (THIBAUDET 1939, p. 179). Marcel Proust viveu pouco essa década, morrendo no fim de 1922, mas sua obra, pelo contrário, teve grande e crescente papel nessa década em que Paris era novamente uma festa e um verdadeiro laboratório do experimentalismo. Logo, se a guerra fora primeiramente sentida como ápice da crise e da decadência, por outro lado possibilitou a superação do passado sentido como retrógrado e estagnante e a construção de um novo mundo admirável.

Os exemplos até aqui mostraram que a obra de Proust foi recepcionada e difundida como um dos principais (se não o maior) acontecimento literário da França do pós-guerra. Tal juízo foi se estabelecendo ao longo do século $\mathrm{XX}$, e a crítica inclusive tendeu a ver a obra de Proust, ladeada pela de outros escritores como Joyce, Virginia Woolf, Kafka, entre outros, como um dos grandes cânones do alto modernismo desse início do século XX. Testemunho, memória, história da sociedade, Em busca do tempo perdido foi visto diversas vezes, pelos contemporâneos de sua longa publicação, como uma representação válida da sociedade parisiense sob a Terceira República. Mas, no momento em que a obra de Proust foi envolvida nesses debates sobre vanguarda artística e representação da realidade, isso acabou a comprometendo também em outras questões que diziam menos respeito aos problemas puramente estéticos da literatura e do romance.

Isso mostra que nesse período de difusão sem igual da imprensa e do mercado editorial, por meio de jornais, revistas e edições de livros em grandes tiragens, no qual as artes em geral se tornavam objeto de debates intermináveis, as querelas surgidas quando da publicação dos volumes de Em busca do tempo perdido traziam consigo problemas e questões importantes do contexto mais amplo. Ao falarem desse romance nesses termos, fica evidente como os 
comentadores se engajavam e engajavam o próprio texto alheio em questões muito mais abrangentes que diziam respeito à cultura, à política, à economia e à sociedade francesas e, mais especificamente, parisienses. Tratava-se de discussões intrínsecas à historicidade específica dessas décadas da Terceira República Francesa que não só foram vividas e narradas por Proust, mas que também faziam parte da conjuntura que acolheu os diversos volumes de seu longo ciclo romanesco.

\section{Referências bibliográficas}

AUERBACH, E. Mimesis: a representação da realidade na literatura ocidental. São Paulo: Perspectiva, 1976.

BINET-VALMER. La Semaine Littéraire. Comoedia, 5 out. 1919.

BRADBURY, M. O mundo moderno. Dez grandes escritores. São Paulo: Companhia das Letras, 1989.

CHAUMEIX, A. Le roman et la peinture de la société. Revue de deux mondes, Paris, p. 691-701, 10 abr. 1928.

COMPAGNON, A. La Recherche du Temps Perdu de Marcel Proust. In: NORA, P. (dir.) Les Lieux de mémoire. Tome III: Les France. 2. Traditions. Paris: Gallimard, 1992.

FAŸ, B. Panorama de la littérature contemporaine. Paris: Simon Kra, 1925. FERNANDEZ, R. Marcel Proust. Les Cahiers du Mois, p. 202-205, 1926.

FOUCAULT, M. As palavras e as coisas: uma arqueologia das ciências humanas. São Paulo: Martins Fontes, 1992.

Um diálogo sobre os prazeres do sexo: Nietzsche, Freud e Marx. Theatrum philosoficum. São Paulo: Landy, 2005.

História da sexualidade I: a vontade de saber. Rio de Janeiro: Graal, 2001.

GAY, P. Modernismo: o fascínio da heresia. De Baudelaire a Beckett e mais um pouco. São Paulo: Companhia das Letras, 2009.

A experiência burguesa: da Rainha Vitória a Freud. A educação dos sentidos. São Paulo: Companhia das Letras, 1988.

GIVONE, S. Dizer as emoções. A construção da interioridade no romance moderno. In: MORETTI, F. (org.) O Romance, 1: A Cultura do romance. São Paulo: Cosac Naify, 2009.

HENRY, A. Proust. Balland, 1986.

JAUSS, H. R. Pour une esthétique de la réception. Paris: Gallimard, 2010.

LAFFOREST, R. de; PIREL, E. L'impasse de Proust. La Gazette Française, Paris, 18 out. 1924 a. 
. L'impasse de Proust. La Gazette Française, Paris, 31 out. 1924b.

LE RIDER, J. A modernidade vienense e as crises de identidade. Rio de Janeiro: Civilização Brasileira, 1993.

LefeBVRE, H. Philosophies, Paris, p. 225-227, 15 maio 1924.

LIMA, L. C. Mímeses e modernidade: formas das Sombras. Rio de Janeiro: Graal, 1980.

MASSIS, H. Réflexions sur l'art du roman. Paris: Plon, 1927.

MORETTI, F. Signos e estilos da modernidade: ensaios sobre a sociologia das formas literárias. Rio de Janeiro: Civilização Brasileira, 2007.

NIETZSCHE, F. Humano, demasiado humano: um livro para espíritos livres. São Paulo: Companhia das Letras, 2000.

PIERREFEU, J. de. L'œuvre de Marcel Proust marque le début d'une révolution littéraire. Le Quotidien, Paris, 12 jul. 1926.

PRAVIEL, A. Ceux d'aujourd'hui et ceux de demain: un Analyste Parisien. M. Marcel Proust. Le Correspondant, Paris, p. 75-86, 1923.

QUESNOY, P. F. Le Moralisme de Proust. In : HOMMAGE à Marcel Proust. Le Rouge et le Noir, Paris, p. 94-98, 15 abr. 1928.

RABATÉ, J.M. O estranhamento de uma língua. Os estilos do modernismo. In: MORETTI, F. (org.). O Romance, 1: a Cultura do romance. São Paulo: Cosac Naify, 2009, p. 887-918.

RAGEOT, G. Du Coté de chez Proust. In : . Litterature. Les grandes heures du Théâtre, de la Poésie et de la Chanson. Journal de I'Université des Annales, p. 336-349, 20 set. 1927.

SENNETT, R. O declínio do homem público: as tiranias da intimidade. São Paulo: Companhia das Letras, 1999.

SIMMEL, G. A metrópole e a vida mental. In: VELHO, O. G. (org.) O fenômeno urbano. Rio de Janeiro: Zahar, 1967.

THIBAUDET, A. Réflexions sur la critique. Paris: Gallimard, 1939 [1926]. 